\title{
Sensitivity and specificity of assessment scales of dentin hypersensitivity - an accuracy study
}

\author{
Mariana Oliveira Cotta ROCHA ${ }^{(a)}$ \\ Aléxia Aguiar Carvalho Fonseca \\ CRUZ(a) \\ Daniella Oliveira SANTOS(a) (DD \\ Dhelfeson Willya DOUGLAS-DE- \\ OLIVEIRA(a) $^{(a)}$ \\ Olga Dumont FLECHA(a) \\ Patricia Furtado GONÇALVES(a)
}

(a) Universidade Federal dos Vales do Jequitinhonha e Mucuri - UFVJM, Department of Dentistry, Diamantina, MG, Brazil.

Declaration of Interests: The authors certify that they have no commercial or associative interest that represents a conflict of interest in connection with the manuscript.

Corresponding Author:

Dhelfeson Willya Douglas de Oliveira

E-mail: dhelfeson@hotmail.com

https://doi.org/10.1590/1807-3107bor-2020.vol34.0043

Submitted: November 10, 2019

Accepted for publication: March 25, 2020

Last revision: April 15, 2020
Abstract: The aim of the present study was to compare the sensitivity and specificity of pain scales used to assess dentin hypersensitivity (DH). The preferred scale, and toothbrushing habits of participants were also investigated. This cross-sectional study was conducted with students and employees of a Brazilian Federal University who presented DH. The participants answered a questionnaire about their toothbrushing and drinking habits. Hypersensitive and non-sensitive teeth were submitted to tactile and ice stick stimuli. Then, the subjects marked their pain level in the visual analogue (VAS), numeric scale (NS), faces pain scale (FPS) and verbal evaluation scale (VES). DH was also assessed by Schiff scale (SS). The data were analyzed by Wilcoxon and Chi-Square tests, as well as by ROC curve. The mean age of the sample (56 women, 16 men) was 27.8 years. The most prevalent acidic beverage was coffee $(36.0 \%)$ and the most preferred scale was the NS (47.2\%). The pain level was statistically higher in teeth with $\mathrm{DH}$ compared to teeth without $\mathrm{DH}(\mathrm{p}<0.05)$. The accuracy ranged from 0.729 (SS) to 0.750 (NS). The highest sensitivity value was $81.9 \%$ for NS. The SS presented the highest specificity (91\%). The visual analog, numerical, verbal evaluation, faces pain, and Schiff scales were accurate for $\mathrm{DH}$ diagnosis. The Schiff scale was the preferred scale for DH assessment.

Keywords: Dentin Sensitivity; ROC curve; Data Accuracy; Diagnosis; Pain Measurement.

\section{Introduction}

Dentin hypersensitivity (DH) is a painful sensation commonly reported in daily practice. ${ }^{1} \mathrm{DH}$ can impair the patient's quality of life, as it arises in response to simple day-to-day activities, such as eating and tooth brushing. ${ }^{2}$

$\mathrm{DH}$ pain is acute and has short duration. It occurs when physical, chemical and/or tactile stimuli reach exposed dentin tissue. ${ }^{3}$ Dentin exposure is usually caused by gingival recession, abfraction, abrasion, or erosion, and may not be associated with carious lesions or pulp pathologies. ${ }^{4}$

Pain is a subjective sense and depends on both the physiological process of nerve fibers stimulation, and the psychosocial environment 
in which the individual lives., ${ }^{5,6}$ In the health area, pain measurement is very important for diagnosis and therapeutic approaches.

Considering the multifactorial etiology of $\mathrm{DH}$, the similarity of symptoms with other dental pathologies, and the challenges of measuring pain, several instruments are used to qualify and quantify $\mathrm{DH}$, such as scales and questionnaires (self-reported or not). ${ }^{8}$ This diversity resulted in several studies with no standardized methodology to assess $\mathrm{DH}$, which makes it difficult to compare the results. ${ }^{3} \mathrm{~A}$ consequence might be the wide range of reported prevalence of $\mathrm{DH}$, from $1.34 \%$ to $98 \%$. ${ }^{9,10}$

Several studies have been conducted to investigate the intensity of $\mathrm{DH}$ and the effectiveness of $\mathrm{DH}$ treatment, ${ }^{3,11}$ however, there is a gap in the literature about the sensitivity and specificity of pain scales used to specifically assess DH. ${ }^{6,12,13}$ The aim of the present study was to compare the sensitivity and specificity of pain scales to assess $\mathrm{DH}$. As for secondaries aims, the preferred scale, and toothbrushing and drinking habits were investigated.

\section{Methodology}

\section{Sample}

The present study was conducted at the Periodontics Clinic of Federal University of Jequitinhonha and Mucuri Valleys (UFVJM). The subjects were recruited through patient communications designed to attract study participants. Students and employees of UFVJM who presented DH were enrolled.

The sample size calculation was performed considering the standard deviation of the sensitivity obtained with the visual analog scale $(2.23 \mathrm{~mm}) \cdot{ }^{14}$ The difference to be detected between groups was stipulated to be $1 \mathrm{~mm}$, with a significance level of $95 \%$ and power of $80 \%$. Taking into account a $10 \%$ loss, a sample size of 72 participants would be required.

\section{Eligibility criteria}

Participants over 18 years old presenting DH and who agreed to participate were included. The exclusion criteria were participants using nonsteroidal anti-inflammatory drugs, desensitizing toothpaste, or other desensitizing products, who presented restored or decayed sensitive teeth, or who had dental bleaching treatment in the past 15 days.

\section{DH diagnosis}

The teeth were diagnosed as presenting $\mathrm{DH}$ by clinical examination and anamnesis. $\mathrm{DH}$ was diagnosed if a) the patient reported pain on eating, drinking, or toothbrushing $+b$ ) presented an exposed dentin surface on the affected tooth + (iii) absence of any other tooth pathology could may explain the pain.

\section{DH stimulation}

The tactile stimulus was performed by linearly sliding the tip of the dental probe \#5 from mesial to distal at the cervical region of the buccal surface of the tooth with moderate pressure. To standardize the pressure, the examiner (MOCR) was previously trained and calibrated by using a precision scale to test the strength (ICC: 0.899), and practicing on a wax blade in order to produce regular and similar deformations.

The cold stimulus was performed by applying an ice stick directly over the same area for three seconds. Both tactile and cold stimuli were applied to teeth presenting $\mathrm{DH}$ and teeth without $\mathrm{DH}$ in the same participant.

Firstly, the tactile stimulus was applied in teeth with $\mathrm{DH}$ and in their homologous without $\mathrm{DH}$. Then, the cold stimulus was performed, in the same way. If the homologous tooth also presented $\mathrm{DH}$, an alternative tooth without $\mathrm{DH}$ was selected within the same group (incisors, canines, premolars or molars). Each stimulus was applied once in each tooth.

Teeth without DH were assessed in order to facilitate the ROC curve analysis and to serve as control. The interval between stimuli was 1 minute, long enough to cease the painful sensation of the prior stimulus.

After each stimulus, the participants were instructed to report the intensity of $\mathrm{DH}$ pain in the following scales: visual analogue scale (VAS), numerical scale (NS), faces pain scale (FPS), verbal evaluation scale (VES), and Schiff scale (SS) (Figure 1). The order of the scales was randomized. 
A

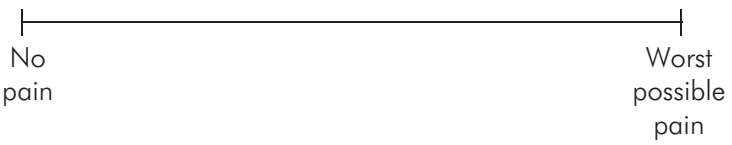

B

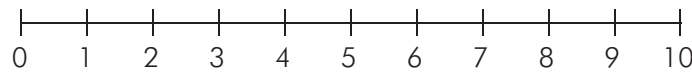

C

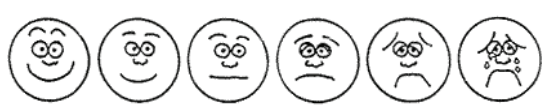

D

None Mild Moderate Severe

Figure 1. DH scales. A) Visual analogue scale B) Numeric scale C) Faces pain scale D) Verbal evaluation scale.

\section{Visual analogue scale (VAS)}

The VAS comprises a horizontal line of $10 \mathrm{~cm}$, anchored by 2 verbal descriptors in its ends: "no pain" on the left, and "worst possible pain" on the right (Figure 1A). The patient made a mark on the line representing the $\mathrm{DH}$ pain sensation. Then, the distance from the left end to the mark made by the patient measured with an analog caliper is the pain intensity. ${ }^{15}$

\section{Numeric scale (NS)}

This scale consists of 11 numbered items that are arranged in ascending order from 0 to 10 , where 0 means no pain and 10 most severe pain (Figure 1B). The participant marked the number that represented their self-assessed DH pain. ${ }^{16}$

\section{Faces pain scale (FPS)}

The FPS is a set of facial expression drawings to illustrate each stage of pain intensity (Figure 1C). ${ }^{17}$ The patient was asked to choose the face that best represented his/her current state. ${ }^{18}$

\section{Verbal evaluation scale (VES)}

The VES comprises a list of adjectives used to describe pain intensity, in an increasing way (Figure 1D). The most common words used are: no pain, mild pain, moderate pain, and severe pain. The subject chose that one that best defined his/her pain. ${ }^{15}$

\section{Schiff scale (SS)}

This scale evaluates the degree of $\mathrm{DH}$ pain according to the patient stimulus reaction. In theSS, the participant is scored from 0 to 3 as follow: 0 - subject does not respond to stimulus; 1 - subject responds to stimulus, but does not request discontinuation of stimulus; 2 - subject responds to stimulus and requests discontinuation or moves away from stimulus; 3 - subject responds to stimulus, considers it to be painful, and requests discontinuation of the stimulus. ${ }^{19}$ This scale is filled out by the operator.

Data about age, gender, handedness, alcohol drinking habits, toothbrushing habits, frequency of acidic beverages consumption and preferable scale were collected.

\section{Statistical analysis}

Statistical analyses were performed using the Statistical Package for the Social Sciences ${ }^{\circledR}$ (SPSS IBM Corp., Armonk, US), version 25. Initially, the variables were analyzed by descriptive statistics.

The normality and homogeneity of variance of data were verified by the Kolmogorov-Smirnov and Levene tests, respectively. The Wilcoxon test was used to compare teeth with and without DH by using the mean scores obtained with the quantitative scales (NS and VAS). The proportion of teeth with and without DH distributed at each level of the categorical scales (PFS, VES and SS) was compared using the Chi-Square test. For statistical analysis purposes, the categorical scales were dichotomized by the median into two categories of $\mathrm{DH}$ levels as follow: PFS - Faces 0 and 1 were grouped into "low $\mathrm{DH}^{\text {", }}$ Faces 2 to 5 were grouped into "high DH"; VES - No pain and mild pain were grouped into "low $\mathrm{DH}^{\text {", }}$ moderate and severe pain were grouped into "high $\mathrm{DH}^{\prime}$; SS - score 0 was grouped into "low $\mathrm{DH}^{\prime}$, scores 1 to 3 were grouped into "high $\mathrm{DH}^{\prime}$.

ROC (receiver operating characteristic) curve analysis was used to compare and evaluate the accuracy of diagnosis, sensitivity and specificity of each scale. The significance level adopted was $5 \%$.

\section{Ethical principles}

This study was approved by the Ethics Committee of UFVJM (approval \#74432117000005108), and 
conducted according to the Helsinki Declaration (1975), revised in 2013. The subjects participated voluntarily and signed a consent form prior to the beginning of the study. At the end of the study, the participants received $\mathrm{DH}$ treatment.

\section{Results}

Fifty-six women (77.8\%) and 16 men (22.2\%) participated totaling 288 teeth (144 with and 144 without $\mathrm{DH}$ ) and 1,440 DH scales. The mean age was 27.8 years old $( \pm 9.3)$. The sample was made up of 61 right-handed (84.7\%), 8 left-handed, and 3 ambidextrous $(4.2 \%)$ people.

Table 1. Toothbrushing habits of the participants.n(\%).

\begin{tabular}{ccc}
\hline Brush bristles & $\begin{array}{c}\text { Bristles deformation } \\
\text { time (days) }\end{array}$ & $\begin{array}{c}\text { Self-reported force } \\
\text { applied to brushing }\end{array}$ \\
\hline Soft & 15 & Very strong \\
$48(66.7)$ & $2(2.8 \%)$ & $6(8.3)$ \\
Medium & $16-30$ & Strong \\
$18(25.0)$ & $24(33.3)$ & $15(20.8)$ \\
Hard & $31-60$ & Middle \\
$6(8.3)$ & $26(36.1)$ & $38(52.8)$ \\
& $>60$ & Weak \\
& $20(27.8)$ & $13(18.1)$ \\
\hline
\end{tabular}

Daily intake of acid beverages was reported by 47 (65.3\%) participants; 22 (30.6\%) and $3(4.2 \%)$ participants reported drinking acid beverages weekly and monthly, respectively. The most prevalent types of acid beverages were: coffee $(36.0 \%)$, citric juices $(33.0 \%)$, soft drinks $(15.0 \%)$, tea $(9.0 \%)$, energy drinks (5.0\%), and isotonic drinks (2.0\%). Forty-five (62.5\%) participants declared consuming alcoholic beverages. Table 1 shows the characteristics of tooth brushing.

The pain level was statistically higher in teeth with $\mathrm{DH}$ compared to teeth with no $\mathrm{DH}$, based on the assessment with NS $(p<0.001)$ and VAS $(p<0.001)$ scales. The statistics (Wilcoxon test) for these quantitative variables is shown on Table 2. Statistically significant differences were also found for FPS $(p<0.001)$, VES $(p<0.001)$, and SS scales $(\mathrm{p}<0.001)$ between $\mathrm{DH}$ and non-DH teeth. The statistics (Chi-Square test) for these categorical variables is shown on Table 3.

The preferred scale was NS (47.2\%), followed by VAS (30.6\%), FPS (16.7\%), and lastly, the VES (5.6\%).

The accuracy was 0.747 (95\%CI: 0,690-0,805) for the VAS; 0.750 (95\%CI: 0.693-0.808) for the NS; 0.743 (95\%CI: 0.685-0.801) for the FPS; 0.743 (95\%CI: 0.685-0.801) for the VES; and 0.729 (95\%CI: 0.670-0.787) for the SS. The sensitivity and specificity of the VAS was $80.6 \%$

Table 2. Association between hypersensitive teeth and numeric scale and visual analog scale.

\begin{tabular}{|c|c|c|c|c|c|c|}
\hline \multirow{2}{*}{ Variable } & \multicolumn{2}{|c|}{ Numeric scale } & \multirow{2}{*}{$p$-value* } & \multicolumn{2}{|c|}{ Visual analogue scale } & \multirow{2}{*}{$p$-value* } \\
\hline & Mean & SD & & Mean & SD & \\
\hline Hypersensitivity teeth & 4.44 & 3.14 & \multirow{2}{*}{$<0.001$} & 4.14 & 3.23 & \multirow{2}{*}{$<0.001$} \\
\hline No hypersensitivity teeth & 1.69 & 2.74 & & 1.59 & 2.67 & \\
\hline
\end{tabular}

SD: standard deviation. ${ }^{*}$ Wilcoxon test

Table 3. Association between hypersensitive teeth and the faces pain scale, verbal evaluation scale, and Schiff scale.

\begin{tabular}{|c|c|c|c|c|c|c|c|c|c|}
\hline \multirow[b]{2}{*}{ Variable } & \multicolumn{2}{|c|}{ Faces pain scale } & \multirow[b]{2}{*}{$p$-value* } & \multicolumn{2}{|c|}{ Verbal evaluation scale } & \multirow[b]{2}{*}{$p$-value* } & \multicolumn{2}{|c|}{ Schiff scale } & \multirow[b]{2}{*}{$p$-value* } \\
\hline & Faces 0-1 & Faces 2-5 & & $\begin{array}{l}\text { No pain - } \\
\text { mild pain }\end{array}$ & $\begin{array}{l}\text { Moderate pain } \\
\text { - severe pain }\end{array}$ & & Score 0 & Score 1-3 & \\
\hline $\begin{array}{l}\text { Hypersensitivity } \\
\text { teeth }\end{array}$ & $42(28.2)$ & $102(73.4)$ & \multirow{2}{*}{$<0.001$} & $73(37.1)$ & $71(78.0)$ & \multirow{2}{*}{$<0.001$} & $35(26.7)$ & $109(69.4)$ & \multirow[b]{2}{*}{$<0.001$} \\
\hline $\begin{array}{l}\text { No hypersensitivity } \\
\text { teeth }\end{array}$ & $107(71.8)$ & $37(26.6)$ & & $124(62.9)$ & $20(22.0)$ & & $96(73.3)$ & $48(30.6)$ & \\
\hline
\end{tabular}

${ }^{*}$ Chi-square test. 
and $61.1 \%$, respectively, for the cutoff point of 0.45 . The cutoff point of 1 for NS presented sensitivity of $81.9 \%$ and specificity of $57.6 \%$. FPS face number 1 presented sensitivity and specificity of $70.8 \%$ and $74.3 \%$, respectively. The VES presented $49.3 \%$ sensitivity and $86.1 \%$ specificity for 'mild pain' response. The cutoff point of 1 in the SS showed 75.7\% sensitivity and $91 \%$ specificity (Figure 2).

\section{Discussion}

DH is a very common painful condition characterized by acute pain. ${ }^{20,21}$ The present study seems to be pioneer, since there is no previous study with the specific aim of measuring sensibility and specificity of pain scales for $\mathrm{DH}$ assessment. The scales used herein were shown to be accurate and sensitive, and should be used in further $\mathrm{DH}$ studies.

A scale that is extremely sensitive and has low specificity covers more positive cases, but presents a greater chance of including false positive cases. Otherwise, a scale that is very specific and has low sensitivity will detect with certainty negative cases, but can generate false negative results for sick patients. For a scale to be considered the gold standard it must gather the quality of being sensitive, specific, and have a high accuracy. ${ }^{22-23}$ Although the present scales showed good accuracy, they had different sensibility and specificity values suggesting their cautious use in DH studies.

The NS presented the greatest accuracy, being able to correctly identify DH in $75 \%$ of the cases. However, the values obtained by the other scales were a little lower. This slight difference between the values indicates that all scales are accurate and efficient in diagnosing $\mathrm{DH}$. Thus, it is even more important to verify the sensitivity and specificity of each scale to determine the most appropriate one.

The scale that presented the best scores for sensitivity and specificity was the SS. The high values for these two properties allow a diagnosis that encompasses the maximum correct results with fewest false negatives and false positives in relation to the actual diagnosis. This result was expected, considering that the SS was developed specifically for DH assessment. ${ }^{4,19}$ It is also important to note that the SS was the only scale applied by the operator; all other scales were self-responded by the participants.

The SS was created for DH assessment in cases of use of thermal/evaporative stimuli. ${ }^{19}$ In the present work, the SS also showed good results using tactile stimulus. The SS is filled out by the operator, avoiding interpretation and filling biases by the patient, and therefore, of great value in research. Since its

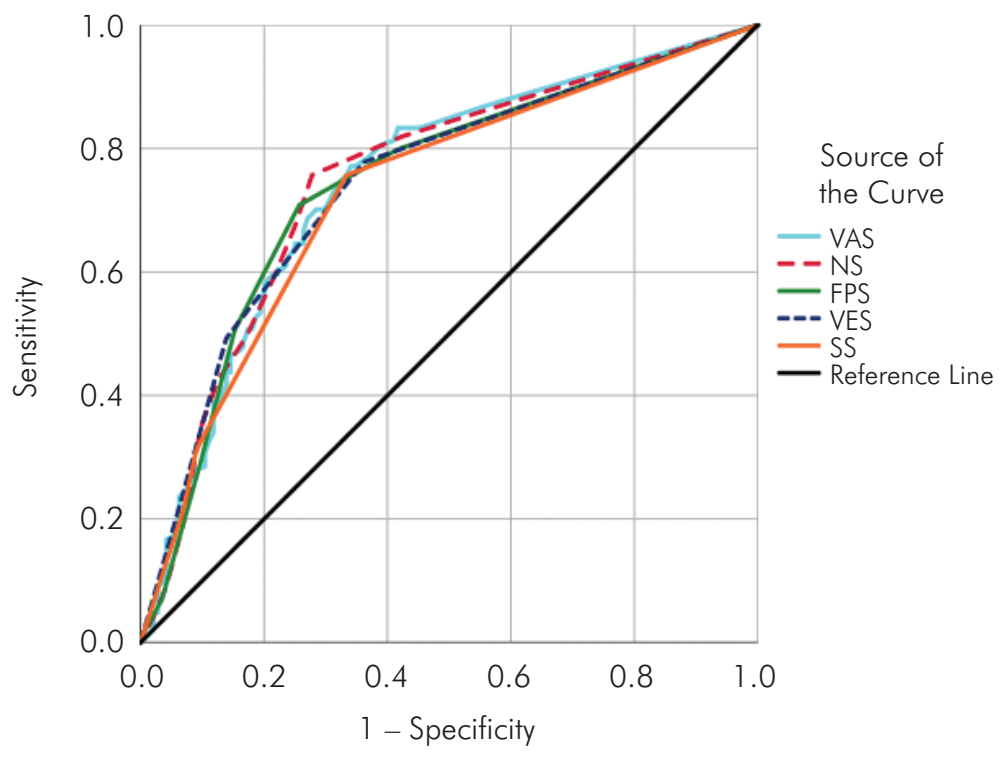

Figure 2. ROC curve analysis of the $\mathrm{DH}$ scales. 
completion is based on the immediate reaction of the patient, it is possible to quickly correlate its outcome to the diagnosis.

The sensitivity and specificity of each scale are based on the cutoff point adopted, i.e., if other cut points were adopted, that values would change. In this study, we considered that the cutoff point on each scale indicates whether the tooth has $\mathrm{DH}$ or not. Considering all vital teeth have natural sensitivity but not all are affected by $\mathrm{DH}^{24,25}$ these cutoff points should be used in future studies and in clinical practice as diagnostic criterion for $\mathrm{DH}$. In other words, if the patient does not reach the cutoff point on a certain scale, then the tooth should not be considered as having $\mathrm{DH}$.

The participants chose NS as the preferred scale, which is probably due to its easy interpretation and use. The NS is a better scale for parametric analyses, in addition to being easy to apply. ${ }^{26}$ At present, the NS presented the highest value for sensitivity and lowest value for specificity indicating it is ideal for true positive diagnoses of $\mathrm{DH}$, however, susceptible to some false negative results compared to other scales.

The mean age of the sample showed that $\mathrm{DH}$ affects a young population. With advanced age, the rate of edentulism increases. In addition, in old adults, the remaining teeth have a larger portion of tertiary dentin, which protects against DH. ${ }^{24,27,28}$

Because toothbrush bristles keep their integrity for a short time and the perception of medium to strong toothbrushing force provides better cleaning, individuals may be susceptible to gingival recession and abrasion that can lead to $\mathrm{DH}$.

The frequency of alcoholic and citric beverages consumption showed that the participants may be strongly subjected to the development of dental erosion. ${ }^{27}$ Coffee was the most consumed beverage.
Although the $\mathrm{pH}$ of coffee is not the lowest among the reported beverages, the amount of its ingestion as well as the frequency along the day may increase its erosive potential, consequently causing $\mathrm{DH} .{ }^{30,31}$

Based on the DH assessment scales, it is recommended that in future studies, the following criteria for DH diagnosis be adopted: VAS - score greater than 0.54; NS - score greater than 1; FPS - face greater than number 1; VES - report of mild pain or higher; SS - score greater than 1 . It is important to emphasize that this suggestion should not replace the clinical examination already established in the literature for $\mathrm{DH}$ diagnosis, ${ }^{4}$ but be complementary to the actual diagnosis. Also, the present criterion focuses on the pain scales for standardization of $\mathrm{DH}$ assessment.

A possible limitation of this study is a sample not representative for the general population. However, the use of a specific population avoids confounding bias.

\section{Conclusion}

The visual analog, numerical, verbal evaluation, faces pain, and Schiff scales were accurate for $\mathrm{DH}$ diagnosis and should be used for $\mathrm{DH}$ assessment. The Schiff scale presented good sensitivity and specificity values in the diagnosis of $\mathrm{DH}$, and should be the preferential scale in assessing DH. Alternatively, the numerical scale could be used since it was the preferred one by the participants and presented great sensitivity value.

\section{Acknowledgments}

The authors thank the support received from the State of Minas Gerais Research Support Foundation (Fapemig). The authors declare that they have no conflict of interest.

\section{References}

1. Goh V, Corbet EF, Leung WK. Impact of dentine hypersensitivity on oral health-related quality of life in individuals receiving supportive periodontal care. J Clin Periodontol. 2016 Jul;43(7):595-602. https://doi.org/10.1111/icpe.12552

2. Douglas-De-Oliveira DW, Lages FS, Paiva SM, Cromley JG, Robinson PG, Cota LO. Cross-cultural adaptation of the Brazilian version of the Dentine Hypersensitivity Experience Questionnaire (DHEQ-15). Braz Oral Res. $2018 ; 32(0): e 37$. https://doi.org/10.1590/1807-3107bor-2018.vol32.0037 
3. Douglas-de-Oliveira DW, Vitor GP, Silveira JO, Martins CC, Costa FO, Cota LO. Effect of dentin hypersensitivity treatment on oral health related quality of life - A systematic review and meta-analysis. J Dent. 2018 Apr;71:1-8. https://doi.org/10.1016/i.jdent.2017.12.007

4. Canadian Advisory Board on Dentin Hypersensitivity. Consensus-based recommendations for the diagnosis and management of dentin hypersensitivity. J Can Dent Assoc. 2003 Apr;69(4):221-6.

5. Hiermstad MJ, Fayers PM, Haugen DF, Caraceni A, Hanks GW, Loge JH, et al. Studies comparing Numerical Rating Scales, Verbal Rating Scales, and Visual Analogue Scales for assessment of pain intensity in adults: a systematic literature review. J Pain Symptom Manage. 2011 Jun;41(6):1073-93. https://doi.org/10.1016/i.jpainsymman.2010.08.016

6. Conti PC, de Azevedo LR, de Souza NV, Ferreira FV. Pain measurement in TMD patients: evaluation of precision and sensitivity of different scales. J Oral Rehabil. 2001 Jun;28(6):534-9. https://doi.org/10.1046/j.1365-2842.2001.00727.x

7. Wan TT, Gurupur V, Patel A. A longitudinal analysis of total pain scores for a panel of patients treated by pain clinics. Health Serv Res Manag Epidemiol. 2019 Apr;6:2333392818788420. https://doi.org/10.1177/2333392818788420

8. Gillam DG. Current diagnosis of dentin hypersensitivity in the dental office: an overview. Clin Oral Investig. 2013 Mar;17(S1 Suppl 1):S21-9. https://doi.org/10.1007/s00784-012-0911-1

9. Guerra F, Corridore D, Cocco F, Arrica M, Rinaldo F, Mazur M, et al. Oral health sentinel-based surveillance: a pilot study on dentinal hypersensitivity pain. Clin Ter. 2017 Sep-Oct;168(5):e333-7. https://doi.org/10.7417/T.2017.2030

10. Cunha-Cruz J, Wataha JC, Heaton LJ, Rothen M, Sobieraj M, Scott J, et al. The prevalence of dentin hypersensitivity in general dental practices in the northwest United States. J Am Dent Assoc. 2013 Mar;144(3):288-96. https://doi.org/10.14219/jada.archive.2013.0116

11. Flecha OD, Azevedo CG, Matos FR, Vieira-Barbosa NM, Ramos-Jorge ML, Gonçalves PF, et al. Cyanoacrylate versus laser in the treatment of dentin hypersensitivity: a controlled, randomized, double-masked and non-inferiority clinical trial. J Periodontol. 2013 Mar;84(3):287-94. https://doi.org/10.1902/jop.2012.120165

12. Ozlem K, Esad GM, Ayse A, Aslihan U. Efficiency of lasers and a desensitizer agent on dentin hypersensitivity treatment: a clinical study. Niger J Clin Pract. 2018 Feb;21(2):225-30. https://doi.org/10.4103/njcp.njcp_411_16

13. Heft MW, Litaker MS, Kopycka-Kedzierawski DT, Meyerowitz C, Chonowski S, Yardic RL, et al. Patient-centered dentinal hypersensitivity treatment outcomes: results from the national dental PBRN. JDR Clin Trans Res. 2018 Jan;3(1):76-82. https://doi.org/10.1177/2380084417742099

14. Moslemi N, Johari M, Akhoundi MS, Zare H, Shamshiri AR, Khorshidian A. Comparison of desensitizing efficacy of an Iranian dentifrice and a commercially available dentifrice: a randomized double-blinded controlled clinical trial. J Dent (Tehran). 2013 May;10(4):351-7.

15. Williamson A, Hoggart B. Pain: a review of three commonly used pain rating scales. J Clin Nurs. 2005 Aug;14(7):798-804. https://doi.org/10.1111/j.1365-2702.2005.01121.x PMID:16000093

16. Jensen MP. Qual é o número máximo de níveis necessários de medição da intensidade da dor? Dor.1994; 58(4):387-392. [Portuguese]

17. Garra G, Singer AJ, Taira BR, Chohan J, Cardoz H, Chisena E, et al. Validation of the Wong-Baker FACES Pain Rating Scale in pediatric emergency department patients. Acad Emerg Med. 2010 Jan;17(1):50-4. https://doi.org/10.1111/j.1553-2712.2009.00620.x

18. McGrath PA, Seifert CE, Speechley KN, Booth JC, Stitt L, Gibson MC. A new analogue scale for assessing children's pain: an initial validation study. Pain. 1996 Mar;64(3):435-43. https://doi.org/10.1016/0304-3959(95)00171-9

19. Schiff T, Dotson M, Cohen S, De Vizio W, McCool J, Volpe A. Efficacy of a dentifrice containing potassium nitrate, soluble pyrophosphate, PVM/MA copolymer, and sodium fluoride on dentinal hypersensitivity: a twelve-week clinical study. J Clin Dent. 1994;5(Spec No):87-92.

20. Barroso NF, Alcântara PM, Botelho AM, Douglas-de-Oliveira DW, Gonçalves PF, Flecha OD. Prevalence of self-reported versus diagnosed dentinal hypersensitivity: a cross-sectional study and ROC curve analysis. Acta Odontol Scand. 2019 Apr;77(3):219-23. https://doi.org/10.1080/00016357.2018.1536804

21. Alcântara PM, Barroso NF, Botelho AM, Douglas-de-Oliveira DW, Gonçalves PF, Flecha OD. Associated factors to cervical dentin hypersensitivity in adults: a transversal study. BMC Oral Health. 2018 Sep;18(1):155. https://doi.org/10.1186/s12903-018-0616-1

22. Akobeng AK. Understanding diagnostic tests 1: sensitivity, specificity and predictive values. Acta Paediatr. 2007 Mar;96(3):338-41. https://doi.org/10.1111/j.1651-2227.2006.00180.x

23. MaX, Nie L, Cole SR, Chu H. Statistical methods for multivariate meta-analysis of diagnostic tests: an overview and tutorial. Stat Methods Med Res. 2016 Aug;25(4):1596-619. https://doi.org/10.1177/0962280213492588

24. Carvalho TS, Lussi A. Age-related morphological, histological and functional changes in teeth. J Oral Rehabil. 2017 Apr;44(4):291-8. https://doi.org/10.1111/joor.12474

25. West N, Seong J, Davies M. Dentine hypersensitivity. Monogr Oral Sci. 2014;25:108-22. https://doi.org/10.1159/000360749

26. Ferreira-Valente MA, Pais-Ribeiro JL, Jensen MP. Validity of four pain intensity rating scales. Pain. 2011 Oct;152(10):2399-404. https://doi.org/10.1016/i.pain.2011.07.005

27. Splieth CH, Tachou A. Epidemiology of dentin hypersensitivity. Clin Oral Investig. 2013 Mar;17(S1 Suppl 1):S3-8. https://doi.org/10.1007/s00784-012-0889-8 
- Sensitivity and specificity of assessment scales of dentin hypersensitivity - an accuracy study

28. Moraschini V, Costa LS, Santos GO. Effectiveness for dentin hypersensitivity treatment of non-carious cervical lesions: a meta-analysis. Clin Oral Investig. 2018 Mar;22(2):617-31. https://doi.org/10.1007/s00784-017-2330-9

29. Trushkowsky RD, Garcia-Godoy F. Dentin hypersensitivity: differential diagnosis, tests, and etiology. Compend Contin Educ Dent. 2014 Feb;35(2):99-104.

30. Kitchens M, Owens BM. Effect of carbonated beverages, coffee, sports and high energy drinks, and bottled water on the in vitro erosion characteristics of dental enamel. J Clin Pediatr Dent. 2007;31(3):153-9. https://doi.org/10.17796/icpd.31.3.11571653+8206100

31. Grippo JO, Simring M, Schreiner S. Attrition, abrasion, corrosion and abfraction revisited: a new perspective on tooth surface lesions. J Am Dent Assoc. 2004 Aug;135(8):1109-18. https://doi.org/10.14219/jada.archive.2004.0369 